\title{
AN IMMUNOLOGICAL CROSS REACTION BETWEEN MONKEY GONADOTROPHIN PREPARATIONS AND ANTISERA TO HUMAN GONADOTROPHINS
}

\author{
L. WIDE AND J. NEWTON* \\ Department of Clinical Chemistry, University Hospital, Uppsala, Sweden
}

(Received 20th February 1970, revised 4th Fune 1971)

There is still some confusion about the ability of monkey and human gonadotrophins to cross react in immunological systems. McGarry \& Beck (1963), using a haemagglutination inhibition technique, found a cross reaction between antisera to human FSH and monkey FSH. They also found a similar cross reaction with LH. Neill, Peckham \& Knobil (1967), Bagshawe, Orr \& Godden (1968) and Faiman, Ryan, Greslin \& Reichert (1967), using radioimmunoassays, were unable to show a cross reaction between monkey preparations and antisera to human gonadotrophins, while Tullner, Rayford \& Ross (1969), using an antiserum to HGG, found evidence for similar antigenic determinants in gonadotrophins from urine of man and monkey. These contradictory results may be explained by differences in the particular antisera used in the experiments.

Using radioimmunoassays developed for estimating human FSH, LH and HCG with antibodies coupled to an insoluble polysaccharide, urinary material from Rhesus monkeys (Macaca mulatta) was investigated. The Rhesus monkey material consisted of (a) ten urine samples collected randomly during the menstrual cycle, (b) acetone-alcohol-ether extracts (Wide, 1962) of the ten urine samples, (c) kaolin-acetone extracts of two urine pools: one extract, $\mathrm{O}$, from oophorectomized Rhesus monkeys and one extract, F, from monkeys in the follicular phase of the cycle, (d) an alcohol-ether extract, C, from pooled urine of oophorectomized monkeys, and (e) a monkey pituitary gonadotrophin extract. The material was dissolved and diluted in tris buffer of $\mathrm{pH} 7 \cdot 4$ before being assayed.

We have used the radioimmunosorbent technique as previously described by Wide \& Porath (1966) and Wide (1969), using a highly purified human pituitary FSH and LH preparation (Roos, 1968) and an HGG preparation (13,000 i.u./mg, Leo AB, Sweden) as labelled antigens. All the monkey material was examined for ability to inhibit the reaction in three systems: an FSH system with labelled human FsH and anti-human FSH, an LH system with labelled human LH and anti-human LH, and an HCG system with labelled HCG and anti-HCG.

It was found that both the monkey urine samples and the extracts of monkey urine could inhibit the reaction of the LH system and the HCG system. There was good agreement between the slopes of the dose response curves (Text-fig. 1) for the urinary monkey extracts and that of the 2nd International Reference

* Present address : Kings College Hospital, London. 
Preparation for human menopausal gonadotrophins (2nd IRP-HMG). When the activities of the ten monkey urine samples were expressed in unit equivalents of the 2nd IRP-HMG, the values varied between 1 and 88/24-hr urine volume. The dose-response curves for serial dilution of the unextracted urine samples were not always in parallel with those of the urinary extracts, indicating that the unextracted urine contained components other than the cross-reacting material which could interfere in the reaction. The accuracy of the acetone-alcoholether extraction procedure was tested with recovery experiments where extracts $\mathrm{O}, \mathrm{F}$ and $\mathrm{C}$ were added to monkey urine. The recovery varied between $80 \%$

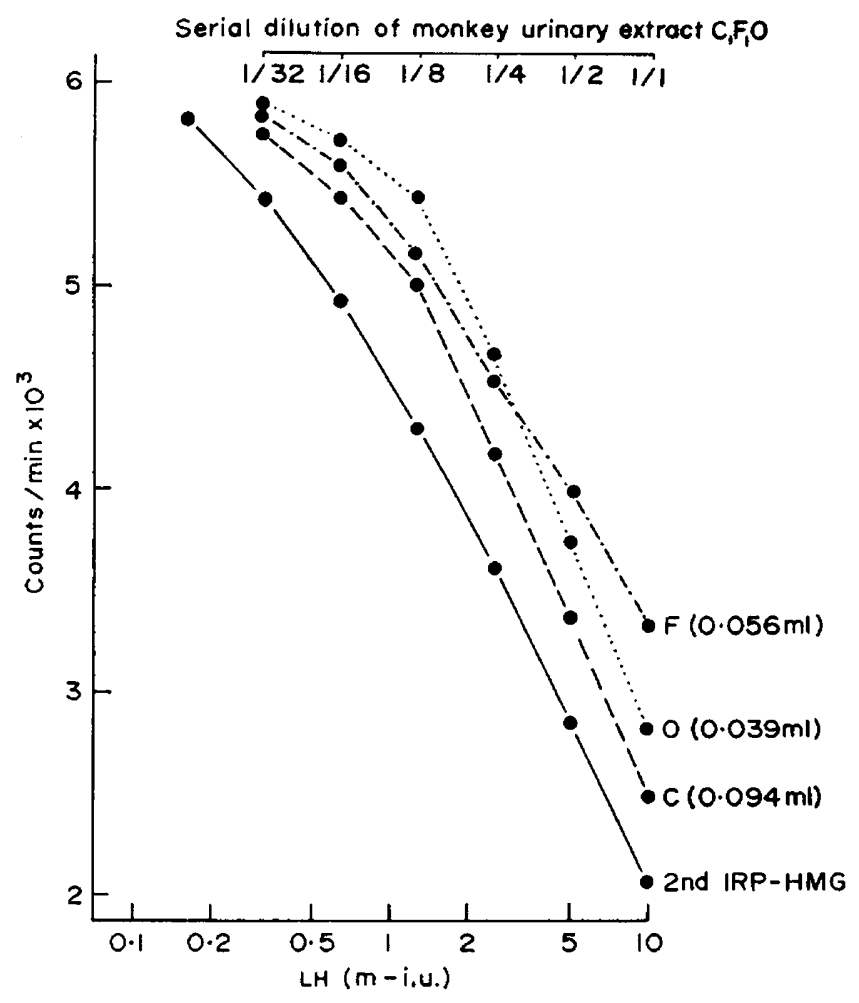

TEXT-FIG. 1. Assay of 'LH' activity in Rhesus monkey urinary extracts. Comparison of doseresponse curves for HMG and three simian urinary extracts. $\mathrm{F}=$ kaolin-acetone extract of urine from monkeys in follicular phase of cycle. $\mathrm{O}=$ kaolin-acetone extract of urine from oophorectomized monkeys. $\mathrm{C}=$ alcohol-ether extract of urine from oophorectomized monkeys.

and $95 \%$ with a mean of $87 \%$. The results obtained with the LH, FSH and HGG systems were similar in this respect.

Of the monkey urinary extracts tested in the FSH system, only the three extracts of urine pools gave a significant inhibition of the reaction, the doses corresponding to 0.1 to $0.7 \mathrm{ml}$ of the pooled urine. There was no parallelism between the slopes of the dose response curves for these extracts and that of the HMG preparation; the latter giving a much steeper slope (Text-fig. 2).

When the monkey pituitary extract was tested in doses of 16 to $64 \mu \mathrm{g}$, an 
inhibition of the reaction of all the three systems was also found. However, the dose-response curve for this material was less steep than that of the HMG preparation or the urinary extracts.

Girard \& Greenwood (1968), using a radioimmunoassay for growth hormone, found that urea and sodium chloride could mimic the effects of growth hormone in urine. To see if there was an interference effect of small molecules with monkey urinary extracts, experiments were carried out using gel filtration on a Sephadex G-75 column before radioimmunoassay. The results showed that the

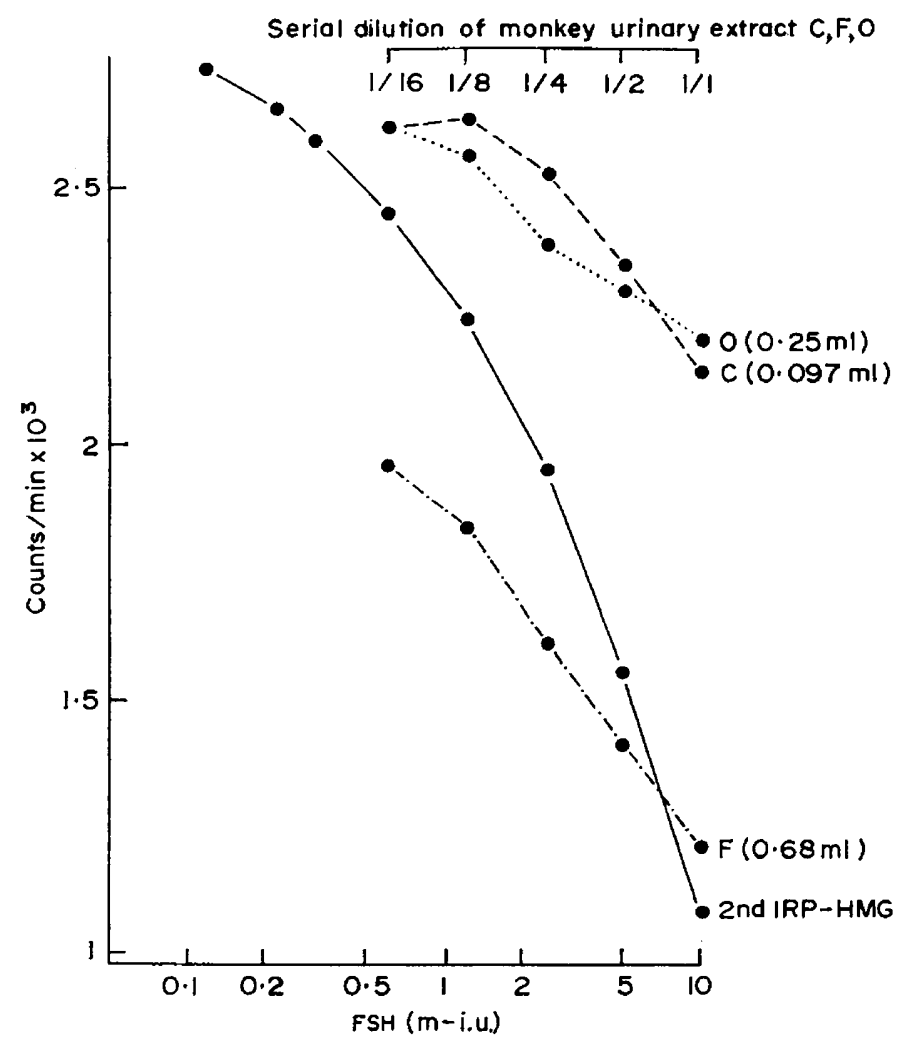

TEXT-FIG. 2. Assay of 'FSH' activity in Rhesus monkey urinary extracts. Comparison of dose-response curves for HMG and three simian urinary extracts. F, $O$ and $C$, as for Textfig. 1 .

inhibiting activity was present in the 'protein' fraction, while the salt fraction was inactive. The monkey urinary extracts were also tested in a solid phase sandwich technique (Wide, 1970) with anti-HGG antibodies coupled to cellulose particles and ${ }^{125} \mathrm{I}$-labelled anti-HGG antibodies as reagents. Components in the monkey extract were bound to the solid-phase-coupled antibodies and, after washing the solid matrix, the labelled antibodies were added which reacted with the monkey material on the solid phase.

These experiments indicate that the inhibition of the reaction observed in the three systems was due to an immunological reaction between antigens in the 
monkey extracts and antibodies to human gonadotrophins, and not to a nonspecific inhibition. Our results confirm those obtained by McGarry \& Beck (1963) with the haemagglutination inhibition technique and by Tullner $e$ al . (1969) with a radioimmunoassay indicating a cross reaction between human gonadotrophins and substances in monkey gonadotrophin preparations. Neill et al. (1967) were unable to show a cross reaction between monkey pituitary gonadotrophin extracts and antisera to human gonadotrophins. Using a monkey pituitary extract of similar biological potency $\langle$ FSH $=0.55 \times$ NIH-FSH-S1; LH $=0.06 \times$ NIH-LH-S1), we can confirm that, with the doses of $0.5 \mu \mathrm{g}$ used by Neill and his coauthors, there was no sign of a cross reaction and larger doses (16 to $64 \mu \mathrm{g}$ ) significantly inhibited the reaction. These findings indicate the presence of a cross reaction though the shallow slope of the dose-response curve suggests that the reaction is only partial.

From the results obtained with the monkey urinary extracts, it seems as if components in these show a stronger cross reaction with the antisera to human LH and HGG than the material in the monkey pituitary extracts. It seems likely that the cross reactions observed are due to partial similarity in the structure of the gonadotrophic molecules from the two species.

We are indebted to Dr B. M. Hobson, Edinburgh, for urine samples and urinary extracts from Rhesus monkeys, to Professor E. Knobil, Pittsburgh, U.S.A., for the monkey pituitary gonadotrophin extracts, to Dr T. Perklev, AB Leo, Hälsingborg, Sweden, for a highly purified HGG preparation and to Dr P. Roos, Uppsala, Sweden, for highly purified human FSH and LH preparations. This investigation was supported by the Swedish Medical Research Council (16 X-637).

\section{REFERENCES}

BAgshawe, K., OrR, A. H. \& Godden, J. (1968) A sensitive radioimmunoassay for human chorionic gonadotrophin and luteinising hormone. F. Endocr. 42, 513.

Faiman, G., Ryan, R. J., Gresilin, J. G. \& Reichart, L. E. (1967) Species specificity of Fsh and Lh as determined by radioimmunoassay. Proc. Soc. exp. Biol. Med. 125, 1232.

Girard, J. \& Greenwood, F. C. (1968) The absence of intact growth hormone in urine as judged by radioimmunoassay. F. Endocr. 40, 493.

MaGarry, E. E. \& BECK, J. (1963) Some studies with antisera to human FSH. Fertl. Steril. 14, 558.

Neil, J. D., Peckham, W. D. \& Knobil, E. (1967) Apparent absence of immunological cross reactivity between human and simian gonadotrophic hormones as determined by radioimmunoassay. Nature, Lond. 213, 1014.

Roos, P. (1968) Human follicle stimulating hormone. Acta endocr., Copenh. Suppl. 131.

Tullner, W. W., RAyFord, P. L. \& Ross, G. T. (1969) Evidence for similar antigenic determinants in gonadotrophins from urine of man and monkey (Macaca mulatta). Endocrinology, 84, 908.

WiDE, L. (1962) Immunological assay of HGG. Acta endocr., Copenh. Suppl. 70.

WwE, L. (1969) Radioimmunoassays employing immunosorbents. In: Immunoassay of Gonadotrophins. Acta endocr., Copenh. Suppl. 142, 207.

Wide, L. (1970) Solid phase antigen antibody systems. In: Radioimmunoassay Methods, p. 199. Eds. K. E. Kirkham and W. M. Hunter. Livingstone, Edinburgh.

WIDE, L. \& PORATH, J. (1966) Radioimmunoassay of proteins with the use of sephadex coupled antibodies. Biochim. biophys. Acta, 130, 257. 